\title{
Using Integrating Method to Teach Biochemical Pharmacy Technology
}

\author{
Chunchao Han \\ School of Pharmacy, Shandong University of Traditional Chinese Medicine, Jinan, P.R China. \\ Email: chunchaoh@126.com \\ Received December 20 $0^{\text {th }}, 2009$; revised February $7^{\text {th }}, 2010$; accepted September $16^{\text {th }}, 2010$.
}

\begin{abstract}
An integrating method to teach Biochemical Pharmacy Technology was developed to help students understand the technology to produce biochemical pharmacy well in this paper. By the integrating method, students can compare the main content of the biochemical pharmacy and the technology to produce them. Students were encouraged to demonstrate the connection and difference of the various biochemical pharmacies. The results showed that the performance of students with integrating method is significantly better than that of students without integrating method $(\mathrm{p}<0.05)$. In conclusion, integrating method can enhance students' performance on Biochemical Pharmacy Technology.
\end{abstract}

Keywords: Curricular Innovations, BPT, BP, Integrating Method

\section{Introduction}

Biochemical Pharmacy Technology (BPT) is the major curriculum at the School of Pharmacy, Shandong University of Traditional Chinese Medicine in the fourth-professional year of pharmacy students. At this stage of their education, students typically have difficulty grasping all kinds of Biochemical Pharmaceutics (BP). Many students have learned to rely on rote memorization about course material. However, the performance of them is very poor. Approaches reported to facilitate student learning include intermeshing different teaching modes/strategies, changing the pace of lectures and active learning, all of which are intended to stimulate student thinking and reflection on the subject matter (Matthews, 1997; Ruhl, Hughes, \& Schloss, 1987). Active learning can be approached in numerous ways and, classically, is thought to involve student discussions in small groups (McKeachie, 1999). New method is interactive-learning techniques, such as WebCT quizzes (Duska, 2004). However, none of these methods is about how to learn BPT well.

Integrating method (IM) was selected as a learning process at the School of Pharmacy, Shandong University of Traditional Chinese Medicine since 2004. It involves students in meaningful learning because the process engages possible affiliation of all kinds of Biochemical Pharmaceutics (BP) to students. The learning tends to be long lasting because the new knowledge is related to and integrated within a person's existing knowledge. According to the cognitive learning theory, the brain learns most effectively by relating new experiences and knowledge to prior knowledge, and that meaningful learning requires deliberate effort to link new knowledge with higher-order, more inclusive concepts in a person's cognitive structure (Roth \& Roychoudhury, 1993). The interactive compensatory model for learning (ICML) also suggests that prior knowledge is the most important component when predicting whether new learning will be successful. There is widespread agreement that prior knowledge is the largest factor in successful new learning
(Shapiro, 2004).

\section{Design}

\section{Learning Objectives}

Biochemical Pharmacy Technology (BPT) is designed to provide a preparation and analysis of the Biochemical Pharmaceutics (BP) with an emphasis on the methods to manufacture them.

With the approval of the School of Pharmacy, Shandong University of Traditional Chinese Medicine, a primary objective of the IM was first set. It was to help students acquire and retain a sound biochemical pharmaceutical knowledge base, to learn to use indexing and pharmacy literature resources, to know how to prepare the BP and how to control the quality of them.

\section{Integrating Method (IM) Steps}

The students had learned organic chemistry, biochemistry and pharmacology in the former three-professional years. It was the prior knowledge to the students. Also, the BP grasped by the students was the prior knowledge, the BP will be learnt is the new experiences. One BP by one BP, all the BPS will be grasped by the students eventually (Figure 1).

The main Biochemical Pharmaceutics (BP) may be included in the Table 1. Firstly, from the Table 1, the students can grasp the main BP according to their characteristic.

Secondly, the affiliation and difference of different Biochemical Pharmaceutics (BP) were set up. The affiliation between BPT and the former three subjects was also set up. Figure 2 was the example of Polypeptides.

From 2004, the integrating method was used in teaching of Biochemical Pharmacy Technology. It was taught by one instructor. I compared the performance of students taught using an integrating method or a traditional lecture format on traditional exams. 


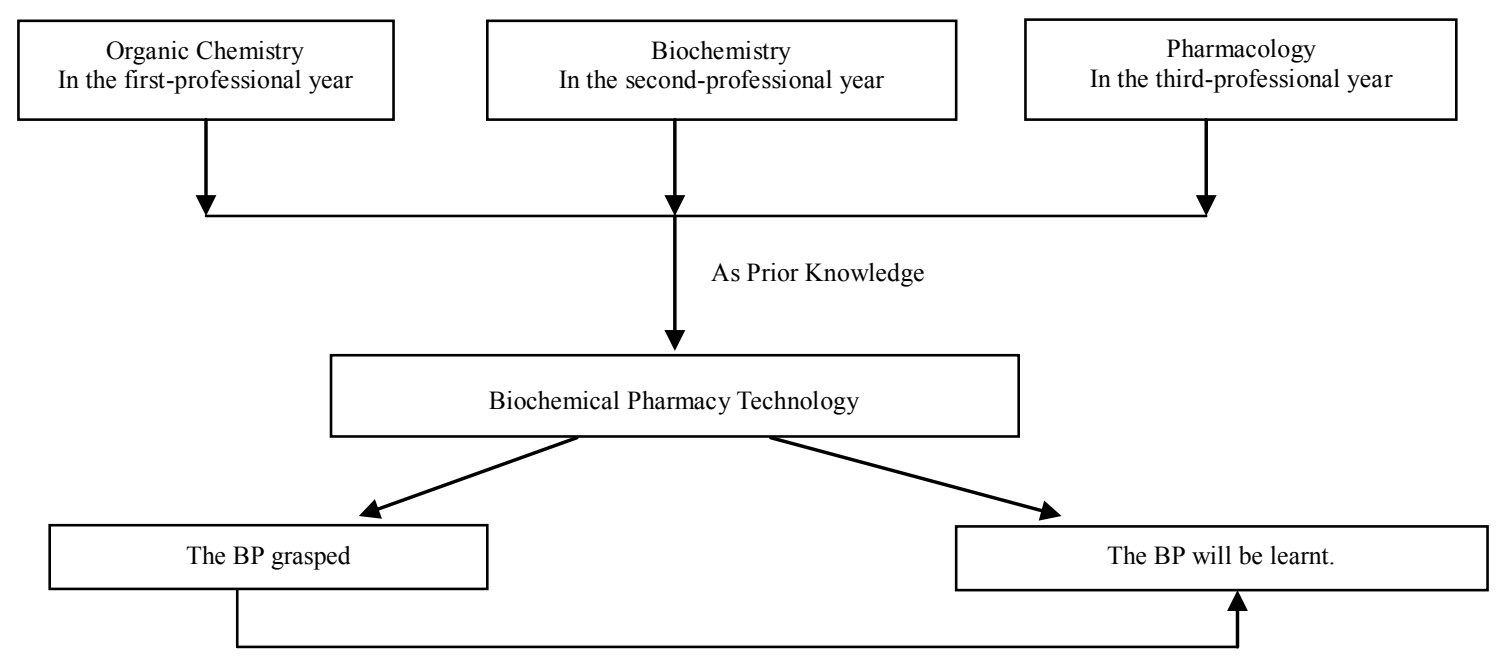

As Prior Knowledge

Figure 1.

The organic chemistry, biochemistry and pharmacology were the prior knowledge to the students. Also, the BP grasped by the students was the prior knowledge to the BP will be learnt.

Table 1.

The main Biochemical Pharmaceutics (BP) in BPT.

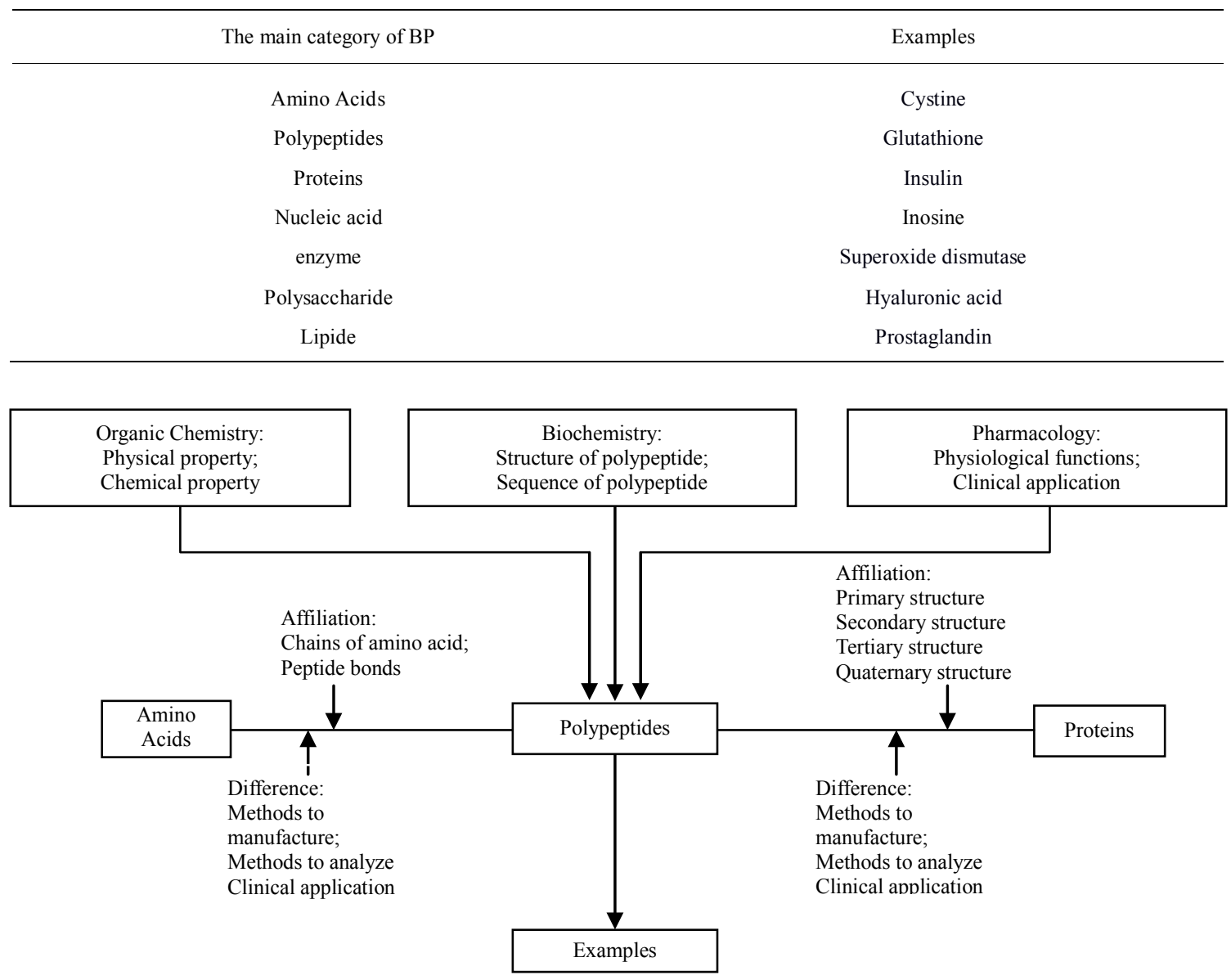

Figure 2.

An example of the affiliation between different BP and the former three subjects. 
Table 2.

The compare of the assessment with different teaching modes.

\begin{tabular}{cccc}
\hline groups & Results \% (2004) & Results \% (2005) & Results \% (2006) \\
\hline group A & $68.7 \pm 2.88^{*}(\mathrm{~N}=46)$ & $69.6 \pm 1.87^{*}(\mathrm{~N}=75)$ & $65.6 \pm 3.79^{*}(\mathrm{~N}=52)$ \\
group B & $61.5 \pm 2.33(\mathrm{~N}=46)$ & $62.5 \pm 2.23(\mathrm{~N}=75)$ & $59.5 \pm 3.10(\mathrm{~N}=52)$ \\
\hline
\end{tabular}

The asterisks indicate a statistical difference $(\mathrm{p}<0.05)$

\begin{abstract}
Assessment
Curricular innovations are usually conducted in small test groups that can be evaluated concurrently with the standing teaching model. In this study, the students were randomly allocated equally into 2 groups (Table 2). The contents of BPT were introduced with integrating method in group A. While in group B, normal teaching modes was used. At the end of term, both groups were assessed with the same test questions. Statistical analysis of results was conducted using SPSS 11.0 software. The data represents means and standard deviations. The significant level of 5\% $(p<0.05)$ was used as the minimum acceptable probability for the difference between the means (Table 2). The results showed that the score of group A with integrating method is significantly different from that of group $\mathrm{B}(p<0.05)$.
\end{abstract}

\section{Conclusion}

The results of this study indicate that an integrating method helped students improve their knowledge of course material better than a traditional lecture format.

Within the last 50 years many universities, colleges, and schools have sought to enhance educational quality through the establishment of departments or services to support the excellence of teaching, learning, and assessment. Madeline Hunter (1994) developed the mastery teaching model, which states that effective teachers use a methodology when planning and presenting a lesson. It follows the philosophy of "tell them what you are going to say, say it, then tell them what you said" with the purpose of providing information within a lesson structure to encourage students to attain stated outcomes or objectives deemed relevant for mastery. Cognitive theories of learning focus on the mind (the mind is a "black box" according to behaviorist views), and attempt to model how information is received, assimilated, stored, and recalled (Lefrançois, 1988). According to the cognitive learning theory, the brain learns most effectively by relating new experiences and knowledge to prior knowledge, and that meaningful learning requires deliberate effort to link new knowledge with higher-order.

Integrating method involves students in meaningful learning. The results indicate that the integrating method can help students to grasp all kinds of Biochemical Pharmaceutics easily.

\section{References}

Duska, M. (2004). Promoting learning in a health care systems course by multiple teaching methods including internet-based quizzes. American Journal of Pharmaceutical Education, 68, 119-124.

Hunter, M. (1994). Enhancing teaching. New York: Macmillan College Publishing.

Lefrançois, Guy R. (1988). Psychology for teaching: a bear always faces the front. Belmont, CA: Wadsworth Publishing Company.

Matthews, J. C. (1997). Intermeshing passive and active learning strategies in teaching biochemistry. American Journal of Pharmaceutical Education, 61, 388-393.

McKeachie, W. J. (1999). Teaching tips strategies research and theory for college and university teachers. New York: Houghton Mifflin Company.

Roth, W., \& Roychoudhury, A. (1993).The development of science process skills in authentic contexts, Journal of Research in Science Teaching, 30, 127-152. doi:10.1177/088840648701000103

Ruhl, K. L., Hughes, C. A., \& Schloss, P. J. (1987). Using the pause procedure to enhance lecture recall. Teacher Education and Special Education, 10,14-18. doi:10.1177/088840648701000103

Shapiro, A. (2004). How including prior knowledge as a subject variable may change outcomes of learning research. American Educational Research Journal, 41, 159-189._doi:10.3102/00028312041001159 